\title{
Aristotle's Methodology for Natural Science in Physics 1-2: a New Interpretation
}

\author{
Evan Dutmer
}

In this essay I will argue for an interpretation of the remarks of Physics 1.1 that both resolves some of the confusion surrounding the precise nature of methodology described there and shows how those remarks at 184a15-25 serve as important programmatic remarks besides, as they help in the structuring of books 1 and 2 of the Physics. I will argue that "what is clearer and more knowable to us" is what Aristotle goes on to describe in 1.2-namely, that nature exists and that natural things change-his basic starting-point for natural science. This, I shall hope to show, is the kind of "immediate" sense datum which Aristotle thinks must be further analyzed in terms of principles (archai) and then causes (aitia) over the course of Physics books 1 and 2 to lead to knowledge about the natural world. ${ }^{1}$ Such an analysis arrives at, as I shall show, a definition (horismos) of nature not initially available from the starting-point just mentioned (i.e., it is in need of further analysis), and which is clearer by nature. ${ }^{2}$ It is not my aim here to resolve longstanding debates surrounding Aristotle's original intent in the ordering and composition of the first two books of the Physics, nor how the Physics is meant to fit into the Aristotelian corpus taken as a coherent whole, but rather to show that the first two books of the Physics, as they stand, fit with the picture of methodology for natural science presented to us in 1.1 .

\section{Introduction}

In 1.1 of the Physics, Aristotle ostensibly gives us his general framework for a natural science. There he says that knowledge concerning nature (episteme peri phuseos) (and indeed all knowledge) involves "grasp of" or "acquaintance with" its (i) “causes" (aitia), its (ii) "first

\footnotetext{
${ }^{1}$ An interesting consequence of this, and one which I shall not pursue in this paper at any length, is that the progression from what is clearer to us and what is clearer by nature is by necessity a form of revision: i.e., the Physics should not be seen as a work validating the "starting-point" of 1.2 contra the monists, but a work which gradually builds to the language of matter and form as what is clearer by nature.

${ }^{2}$ Viz., what we find at the beginning of 2.1: "this suggests that nature is a sort of source (arche) and cause (aition) of change and remaining unchanged in that to which it belongs primarily of itself, that is, not by virtue of concurrence" (192b20-22).
} 
principles" (archas protas) and its (iii) "elements" (stoicheia) (184a10-16). ${ }^{3}$ Although "elements" comes to be used largely synonymously with "principles" in the succeeding discussion of books 1 and 2 of the Physics, ${ }^{4}$ the distinction between principles (archai) and causes (aitia, aitiai) is a crucial one, and seems to play a predominant role in the ordering and subject matter of the two books.

But, after these opening lines, nearly everything that Aristotle says in the rest of 1.1 is controversial, and has proven notoriously difficult for interpreters of Aristotle's scientific methodology. Aristotle goes on to say:

The natural course is to proceed from what is clearer and more knowable to us, to what is more knowable and clear by nature; for the two are not the same (ou gar tauta hemin te gnorima kai haplos). Hence we must start thus with things which are less clear by nature, but clearer to us, and move on to things which are by nature clearer and more knowable (184a15-25, my emphasis). ${ }^{5}$

Charlton finds this passage and the ones that directly follow it particularly obscure and "cryptic," considering especially how they seemingly contradict what Aristotle has to say in other formulations of his methodology throughout the corpus - in particular, De anima and the Posterior Analytics - and wonders about their relation to the Physics as a whole. ${ }^{6}$ Ross too notes the apparent discrepancies between what is said in Physics 1 and what we find in other of Aristotle's works, and admits that Aristotle's “precise method" for a single method of a science of nature is unclear in 1.1. He discusses how Aristotle's extremely compressed prose here even led Pacius to hypothesize that in fact three different distinct methods for natural science are described in these few opening lines. ${ }^{7}$

And the passage does raise a few natural questions readily apparent to us, independent of previous commentators' confusion. The first is: What does Aristotle think he identifies as "what is clearer and more knowable to us" and "what is more knowable and clear by nature"

\footnotetext{
${ }^{3}$ Listed in order of presentation in Phys. 1.1.

${ }^{4}$ Though in other works it seems as though the stoicheia have an importantly different role to play: e.g., Metaphysics A and elsewhere.

${ }^{5}$ Charlton translation, revised, throughout.

${ }^{6}$ Charlton 51-53.

${ }^{7}$ See Ross 456-8. The methods were the so-called 1) methodus resolutiva a toto integrato ad partes integrantes, 2) methodus divisiva ab universalibus et a notioribus secundum sensum ad particularia, and 3) methodus definitiva a nomine ad definitionem.
} 
in following discussions within Physics 1 and 2? And then next: does Aristotle, over the course of books 1 and 2 of the Physics, follow his own program? Or are these general remarks, though intriguing in their own right, not especially pertinent to the main action of the treatise (or treatises) $?^{8}$ And finally, our the overarching question: what are we to make of these remarks, especially when they have such a place of prominence in the first chapter of Aristotle's principal work on a natural science?

\section{General Outline of the Interpretation}

In this essay I will argue for an interpretation of the remarks of Physics 1.1 that both resolves some of the confusion surrounding the precise nature of methodology described there and shows how those remarks at 184a15-25 serve as important programmatic remarks besides, as they help in the structuring of books 1 and 2 of the Physics. I will argue that "what is clearer and more knowable to us" is what Aristotle goes on to describe in 1.2 - namely, that nature exists and that natural things change- - his basic starting-point for natural science. This, I shall hope to show, is the kind of "immediate" sense datum which Aristotle thinks must be further analyzed in terms of principles (archai) and then causes (aitia) over the course of Physics books 1 and 2 to lead to knowledge about the natural world. ${ }^{9}$ Such an analysis arrives at, as I shall show, a definition (horismos) of nature not initially available

\footnotetext{
${ }^{8}$ I allude to the conclusion of some that Physics 1 perhaps was a standalone treatise with the title peri archon and was appended to the separate Physics only later by Aristotle (or perhaps another editor in the Lyceum) (see Ross 1-6). Another tradition within antiquity was to establish a unity between Physics books 1 and 2 (again, Ross 1-6). Themistius, a Byzantine paraphraser of Aristotle's Physics well-regarded in the Middle Ages, certainly thought so (see Themistius On Aristotle's Physics 1-3, 35.2-3). My essay then broadly fits within this latter "unitarian" tradition. In this essay I won't be addressing this question head-on, though I will mention it in a few instances when it suits my purpose. I shall hope to show that my reading is unaffected either way.

${ }^{9}$ An interesting consequence of this, and one which I shall not pursue in this paper at any length, is that the progression from what is clearer to us and what is clearer by nature is by necessity a form of revision: i.e., the Physics should not be seen as a work validating the "starting-point" of 1.2 contra the monists, but a work which gradually builds to the language of matter and form as what is clearer by nature.
} 
from the starting-point just mentioned (i.e., it is in need of further analysis), and which is clearer by nature. ${ }^{10}$

Here is a brief summary of the view I argue for here: on my reading, the main thread of argument in Physics books 1 and 2 is dominated by the methodology discussed in Physics 1.1 itself, and so follows the general structure demanded by Aristotle's insistence that knowledge results from a definition (horismos) which takes a universal/whole (katholou, holon), more knowable and more clear to us by perception (ten aisthesin), and divides it (diairei) by means of principles (archai) into particulars which are clearer and more knowable by nature (phusei). This structure demands that we start with a universal and that we get clear on the principles needed to divide this universal. This of course is borne out in the actual structure of Physics 1 and 2. The definition comes later at 2.1, after principles for the definition have been adequately discussed and numbered.

It is not my aim here to resolve longstanding debates surrounding Aristotle's original intent in the ordering and composition of the first two books of the Physics, nor how the Physics is meant to fit into the Aristotelian corpus taken as a coherent whole, but rather to show that the first two books of the Physics, as they stand, fit with the picture of methodology presented to us in 1.1, motivating what I call the "physical" approach to Aristotle's Physicsi.e., considering the Physics by its own stated methodological program.

\section{Plan}

I shall argue for the abovementioned points following this order. First, I will give an exposition of the main passages in question, viz., Physics 1.1, and will begin to do some of the work of situating it within the context of Physics 1 and 2 as a whole. In the immediately succeeding section I will introduce and motivate some influential contemporary approaches to the opening remarks of 1.1 and the opposed so-called "dialectical" and "scientific" readings of said remarks. I will then sketch how these approaches suggest we read the Physics as a whole. Contrary to both of these approaches, I shall attempt to make sense of the opening

\footnotetext{
${ }^{10}$ Viz., what we find at the beginning of 2.1: "this suggests that nature is a sort of source (arche) and cause (aition) of change and remaining unchanged in that to which it belongs primarily of itself, that is, not by virtue of concurrence" (192b20-22).
} 
of book 1 without the use of methodological apparatuses from other places in the Aristotelian corpus. I shall hope to show that this feature of my approach is not only distinctive, but attractive. In the third and most important section of my essay, I shall argue for why my approach is the correct one, as it not only makes better sense of the action of the first two books as a whole, but also gives us a far better explanation of some of the seemingly cryptic comments we find in 1.1 (namely, what I had reason to mention in the introduction).

\section{Examining Physics 1.1-2: Aristotle on Episteme regarding Phusis}

I think it will be of some use if I begin our discussion by reproducing the main passage in question which comes at the very beginning of the Physics:

In all disciplines in which there is a systematic knowledge of things with principles, causes, or elements, it arises from a grasp of those: we think we have knowledge of a thing when we have found its primary causes and principles, and followed it back to its elements. Clearly, then, systematic knowledge of nature must start with an attempt to settle questions about principles. The natural course is to proceed from what is clearer and more knowable to us, to what is more knowable and clear by nature; for the two are not the same. Hence we must start thus with things which are less clear by nature, but clearer to us, and move on to things which are by nature clearer and more knowable. The things which are in the first instance clear and plain to us are rather those which are compounded. It is only later, through an analysis of these, that we come to know elements and principles (184a1025).

As I said in my introduction, Aristotle's overall aim with respect to his methodological comments here is far from clear. But it will be useful to give a quick rundown of the less obscure parts of the passage. ${ }^{11}$

Principles (archai), as the word suggests, are prior to anything else in our science of nature, and are the fundamentals out of which explanatorily posterior causes (aitia, "explanations," "reasons") are developed. As we go on to see in 1.2, principles must be principles of something - that is, they must constitute other things so they are not themselves able to have principles — and they must either be one or many (184b14-15). Aristotle, as we shall see, comes down resolutely on the side of their being multiple, though that it is not immediately at hand. Causes (aitia), on the other hand, are other less prior modes of explanation which (it seems) arise out of the principles. In 2.3 they are also revealed to be

\footnotetext{
${ }^{11}$ Though our discussion here is solely meant as an introduction and is by no means exhaustive.
} 
multiple-Aristotle's famous four causes - but that of course is an observation far removed from the reflections of 1.1. At this point it only matters that causes follow principles in a systematic knowledge of nature.

Now, as I said in the introduction, it is very tempting, and indeed plausible, to take the main purpose of 1.1 to be setting up the ordering of books 1 and 2, with book 1 functioning as an investigation into the number and nature of principles for a natural science and book 2 continuing the order of explanation into the number and nature of the natural causes. ${ }^{12}$ Moreover, the topic seems to be picked up somewhat straightforwardly later in the Physics $(2.3,194 b 15-25)$. This, I think, is good as far as it goes. But it leaves the even more cryptic statements that follow Aristotle's quick summary discussion of principles, causes, and elements in 1.1 unexplained.

This starts with Aristotle's recommendation that we begin our study of natural science with what Charlton translates as the "natural course" (lit., pephuke, a verbal form) at 184a16. This approach is "to proceed from what is clearer and more knowable to us, to what is more knowable and clear by nature; for the two are not the same". While this may at first seem intuitively true-science, we think, somehow orders or explains immediately clear perceptions by explanations in mathematical or technical terminology not immediately clear to us, and proceeds by steps to things which are somehow clearer to the way things really are, or, perhaps, how they stand as objective matters of fact - the sentiment is less clearly understood with respect to what Aristotle goes on to do in the succeeding sections of the Physics. In fact, it is not immediately clear just what Aristotle thinks is the sort of thing that is clear to us and the sort that is, by contrast, more knowable by nature.

And this is further complicated by how Aristotle concludes Phys. 1.1, where the progression from what is clearer to us to what is clearer by nature is even more obscure. Aristotle writes:

That is why we should proceed from the universal (katholou) to the particular (hekasta). It is the whole (holon) which is more knowable by perception (kata ten aisthesin), and the universal is a sort of whole: it embraces many things as parts. Words stand in a somewhat similar relationship to

\footnotetext{
${ }^{12}$ See esp. 2.1-3 and apparent back references to the aims and goals of 1.1. Indeed, this seems to be how Simplicius reads the connection between books 1 and 2. He says in his introduction to On Aristotle's Physics 2 that the first book of the Physics "after outlining and examining the doctrines of the natural scientists, proceeded to reveal the elemental principles," and that the second book expounds on the causes, which are more numerous and not themselves "elemental" (259.1-20).
} 
accounts. A word like 'circle' indicates a whole indiscriminately, whereas the definition of a circle divides it into particulars. And little children at first call all men father and all women mother, only later coming to discriminate each of them. (184a23-184b13)

What is perhaps most striking in this passage is Aristotle's insistence that it is with the universal that we ought to begin our account of the natural world rather than the particular, and the immediate implication that the universal is more clear to us and that the particular is clearer by nature. What could Aristotle mean here? For we may at first be tempted to think that Aristotle has got the order completely turned around-science, we think, generally works from particulars to generalized universals, not the other way around. That, we might think, sounds like a hopeless conceptual enterprise-perhaps of interest to the philosopher but not to anyone else. That is, we do not, say, begin with universal meteorological principles about Earth-like atmospheres to give a prediction of weather conditions that might obtain tomorrow in Chicago, but rather work up to better and better generalized laws through a combination of careful, accurate observation and interpreted data analysis. On such a view, the "universal" follows, and ultimately depends on, interpreted particulars.

But how could we read this passage more charitably? Just what would it mean for Aristotle to say that correct scientific procedure demands starting with universals-which are better known to us - to arrive at particulars, which are more clear by nature? Part of the strength of my discussion in this essay, I think, is that I am able to provide an answer to this question.

But the text of 1.1 leaves us with a host of interpretive and philosophical questions besides: are the things that are immediately clear to us - these "universals" - certain received views, endoxa? Or are they, rather, things knowable by perception? What would it mean to perceive a universal? Again: Are the things more knowable by nature arrived at by a sort of a priori, conceptual, dialectical analysis, or by a method more familiarly "scientific" to usproceeding from experience to generalization? In any case, how we choose to answer these questions will make a significant impact on how we view Aristotle's scientific methodology in Physics 1-2 as a whole and serve as a direct transition into my next section. 


\section{5. 'Dialectical' and 'scientific' approaches to Physics 1.1}

In recent approaches to Aristotle's methodology in the Physics, two broad interpretive camps have arisen, each hoping to answer just the sort of questions we had reason to ask in the previous section. I shall take as representative of the so-called "dialectical" interpretation those along the lines of G.E.L. Owen, Terence Irwin, and William Charlton, ${ }^{13}$ and as representative of the scientific approach an influential essay by Robert Bolton, “Aristotle's Method in Natural Science: Physics I," where Bolton consciously sets himself against the trend toward the "dialectical" approach. ${ }^{14}$ I shall begin with the dialectical approach and then discuss the scientific approach.

The dialectical approach is distinguished most of all by its emphasis on the supposed tension between Aristotle's "theory and practice" (to borrow from Owen's characterization): namely, supposed discrepancies between what Aristotle said in the Prior and Posterior Analytics were the criteria for correct methodology in any given science, and Aristotle's practice in the Physics, i.e., how Aristotle arrives at the first principles and causes of a natural science. For it seems that in the Posterior Analytics we get an account of scientific method which describes episteme in terms of a formal-deductive apparatus, not what we might normally think of as empirical science, though not altogether different from it (and, importantly, what Owen and others think Aristotle does not give us in the Physics). Indeed, in the Posterior Analytics Aristotle says that we have scientific knowledge of something when we are able to reason from certain incontrovertible and immediately known premises to their necessitated conclusions. The conclusions of course are then demonstrative, but, avoiding regress, Aristotle says that the "immediately known" premises are themselves indemonstrable. In a useful passage, he writes:

Our own doctrine is that not all knowledge is demonstrative: on the contrary, knowledge of the immediate premises is independent of demonstration. (The necessity of this is obvious; for since we

${ }^{13}$ Though I shall not discuss them all in depth. For Owen, see his classic article, "Tithenai ta phainomena" in Logic, Science, and Dialectic (London and Ithaca, 1962/1986), which I will be discussing in the next few pages. For Irwin, who follows in a similar approach, see Aristotle's First Principles (Oxford, 1988), 3.34-37, and, for our purposes, esp. 34. For Charlton, see his introduction to his translation of the first two books of the Physics, especially pages 11 and 15 .

${ }^{14}$ Bolton, Robert, “Aristotle's Method in Natural Science: Physics I." Aristotle's Physics: A Collection of Essays. Ed. Lindsay Judson. Oxford: Clarendon, 1988. 
must know the prior premises from which the demonstration is drawn, and since the regress must end in immediate truths, those truths must be indemonstrable.) Such, then, is our doctrine, and in addition we maintain that besides scientific knowledge there is its source which enables us to recognize the definitions. (Pos. An. 1.3, 72b18-24)

Now just how these premises are immediately known is a matter of some complexity. But it seems that in the Prior Analytics we get a convincing picture, one in which they ultimately derive from objects of sense perception — ta phainomena:

It falls to experience to provide the principles of any subject. In astronomy, for instance, it was astronomical experience that provided the principles of the science, for it was only when the phainomena were adequately grasped that the proofs in astronomy were discovered. And the same is true of any art or science whatever. (An. Pr. 1.3, 46a17-22) $)^{15}$

Now, to Owen's reading (and those who follow his lead in interpreting the Physics dialectically), Aristotle does nothing of the sort over the course of the Physics. He never consistently refers back to a set of canonical phainomena - that is, objects of sense perception which are taken to be accurate, representative, or privileged in any important sense- and further still he does not even adopt the method of reasoning from sense perceptions at all to conclusions somehow contained within such perceptions. Sense data, Owen thinks, play a somewhat subordinate role to the main line of argument in the Physics, where the premises are instead established by "considering how we ordinarily talk," a method more familiar to students of the method of the Topics, i.e., reasoning from the endoxa, "generally-held opinions," to truth (1. 100a18-20). ${ }^{16,17}$ Owen writes: “ $<\ldots>$ the Physics ranks itself not with physics, in our sense of the word, but with philosophy. Its data are not for the most part the materials not of natural history but of dialectic, and its problems are accordingly not questions

\footnotetext{
${ }^{15}$ Owen's translation at the beginning of his “Tithenai ta phainomena," p. 239.

${ }^{16}$ Using Charlton's phrase on p. xv. See also Wieland, Die aristotelische Physik (Göttingen, 1962), for extensive discussion on this point (also cited in Charlton xv). Charlton has a useful list of instances of ordinary language data on p. xi: Phys. 192b11-12, 194b33-5, 196a15-16, 199a1.

${ }^{17}$ I won't have much to say here about the detailed particulars of either Owen or Charlton's characterization of Aristotle's position as dialectical — or much to say about how it fits with the Topics - but I assume the following sketch of the dialectician in the Topics: he reasons from what is known to either all or by the wise (but what is not itself provable) to what is true (if he is a philosopher) and to what is useful or advantageous (if he is a mere dialectician) (Top. 8. 155b7-10, Charlton xi). On the Owenian reading, then, Aristotle is of course not just a dialectician-he is still a philosopher seeking the truth via the endoxa - but he is not something of a philosopher-scientist hybrid (i.e., someone who reasons from sense perceptions to generalized principles about the natural world).
} 
of empirical fact but conceptual puzzles". ${ }^{18}$ And in another further formulation of similar sentiment Owen cites Mansion: " [In the Physics] <..> in general everything comes down to more or less detailed conceptual analyses - analyses often guided and illustrated by, rather than founded upon, empirical data". ${ }^{19}$

Bolton argues for the nearly opposite conclusion in his "Aristotle's Method in Natural Science: Physics I" and consciously sets himself against the "new orthodoxy" of the dialectical interpretation of the Physics. He is the main proponent of the interpretation I call "scientific", as one of Bolton's main aims is to show that Aristotle's method in the Physics is one we might ordinarily recognize as scientific, in the normal, Baconian sense. He develops his account in part out of an analysis of Physics 1 (which he thinks is underappreciated by Owenian interpreters), but with a strong emphasis on the Posterior Analytics as well, for as it turns out one of his other main points in the essay is to explain away the apparent tension Owen and other dialectical interpreters felt between the Analytics picture of scientific knowledge and the practice of the Physics. Bolton goes so far as to say: "The correspondence between the Physics and the Analytics enables us now to draw a general conclusion about the method which Aristotle recommends in the Physics for natural science, namely that this method is exactly the one he describes in the Posterior Analytics." 20

But why does Bolton say this? For one, he thinks that there is actually a strong resemblance between what Aristotle says in the Posterior Analytics (esp. 1.1-2, 2.9 and 2.19) about scientific method and what Aristotle says in Physics 1.1 and what he goes on to do in the succeeding books of the Physics. By not focusing on the supposed discrepancies between the two and the supposed Topics-like ordinary linguistic data of the Physics, Bolton is able to draw the Posterior Analytics picture of method and that of the Physics much closer and seemingly in broad agreement. He points especially to the following passage from Posterior Analytics 1.2:

We think we understand a thing simpliciter (and not in the sophistic fashion accidentally) whenever we think we are aware both that the explanation because of which the object is is its explanation, and that it is not possible for this to be otherwise. $<\ldots>$ If, then, understanding is as we

\footnotetext{
${ }^{18}$ Owen 242.

${ }^{19}$ Mansion in Introduction a la physique aristotelicienne (Louvain 1946), p. 211., quoted in Owen 1982, p. 240.

${ }^{20}$ Bolton 11.
} 
posited, it is necessary for demonstrative understanding in particular to depend on things which are true and primitive and immediate and more familiar than and prior to and explanatory of the conclusion (for in this way the principles will also be appropriate to what is being proved). <...> Things are prior and more familiar in two ways; for it is not the same to be prior by nature and prior in relation to us, nor to be more familiar and more familiar to us. I call prior and more familiar in relation to us what is nearer to perception, prior and more familiar simpliciter what is further away. (70b9-12, 20-25; 72a1-6)

What we of course notice here is the language of "what is clearer/nearer to us" and "what is clearer/more knowable by nature or further away" which seems to mirror quite closely the discussion we have in Physics 1.1 in a striking way, and a similarly striking repetition of perception's important role to play.

Bolton also criticizes attempts by Owen and others to characterize the method followed in the Physics as dialectic, along the lines of what is discussed in the Topics. For he finds the evidence for such a move exceedingly weak. In Topics 8.5, Aristotle does indeed say that the dialectician will move from premises which are more intelligible than the conclusion, which will be less intelligible (159b8-9, cited in Bolton 12). But this, as Bolton points out, is a weaker point than what both the Physics 1.1 passage and the above Posterior Analytics passage are discussing. Neither discusses a bare dialectical point - that in a given argument one should start with premises simpler than the conclusion that one may convince others more easily and effectively_-but rather a deeper, substantive philosophical point that the correct method in a science of the natural world is to proceed from what is clearer to us to what is clearer by nature.

But Bolton's interpretation, of course, is not without drawbacks of its own. One of the consequences of Bolton's insistence on the strong equivalence of the methodologies of both the Physics and Posterior Analytics is that when there is a seeming contradiction between the two, he often uses the Posterior Analytics to help us reinterpret what is obscure or difficult in the Physics. This of course has its merits, but it betrays Bolton's probable underlying suspicion that the order of priority goes from the Posterior Analytics to the Physics, and not the other way around. For instance, in Bolton's discussion of the Physics view that we are more directly acquainted with the universal than the particular (which flatly contradicts the Posterior Analytics in 1.2 and elsewhere, where we are said to know the particulars first), Bolton points to other passages in the Posterior Analytics (namely, 2.8 and 
2.19) to explain away the tension. ${ }^{21}$ I wonder, on the contrary, whether a more interesting conclusion might be arrived at by looking at the Physics view-namely, that we are more acquainted with the universals than particulars at first—by its own lights.

\section{The Methodology of Physics 1.1: Understanding the Physics on its own terms}

We can now begin our own analysis of Physics 1.1, and explain its place and function in Physics 1 and 2. My reading will be seen to fall squarely within neither of the two previous interpretive camps we had reason to discuss in the last section, but adopts something of a hybrid stance. As I said before, I take it as a positive feature of my account that it does not rely on other things Aristotle has to say about method in other parts of the Aristotelian corpus. I of course do not think that such a practice is unwarranted or unhelpful, but I do think that understanding the Physics solely on its own terms would be useful for resolving some of the puzzles I mentioned at the beginning of this essay. Hence in contrast to the aforementioned "scientific" and "dialectical" approaches, I shall hope to advance something like the "physical" approach to reading Physics 1.1.

I shall now present my plan for this section. I will argue that 1.1 does indeed introduce the methodology that Aristotle himself will use through books 1 and 2 (and, by implication, that he does not covertly revert to the methodologies either of the Topics or Posterior Analytics). To do this, I will first have to give a reading of 1.1 and then weigh my reading against succeeding discussions within the text of Physics 1 and 2. At the end of this discussion I will give a recapitulation of my points and why I think my method ought to be preferred (or at least ought to be used as an augment) to either the dialectical or scientific approach to Aristotle's Physics.

I shall take it as uncontroversial that the very start of 1.1 (viz., 184a10-16) is fairly unambiguous. Principles (archai), as I have said, seem for Aristotle to be the most fundamental things available to us in giving an account of anything, and are the basic building blocks of systematic knowledge concerning any given subject. I take it as fairly clear that they are explanatorily prior to the other two fundamental items Aristotle discusses (namely,

\footnotetext{
${ }^{21}$ See Bolton 10-11.
} 
stoicheia and aitia), as Aristotle says it is clear that a systematic analysis begins with a discussion about principles (184a16, “delon hoti kai tes peri phuseos epistemes peirateon diorisasthai proton ta peri tas archas"). This, I think, is of fundamental importance, however, since it guides the argument of the rest of Book 1. Aristotle starts 1.2 immediately with conceptual analysis concerning principles. I shall return to causes in a moment after further discussion of 1.1.

In the passage directly following the first sentence, interpreting what Aristotle means becomes considerably more difficult. ${ }^{22}$ Aristotle says that the correct procedure is to start with what is clearer and more knowable to us (gnorimoteron hemin; saphesteron) to those things which are clearer (saphestera) and more knowable (gnorimotera) by nature (phusei). I take it as fairly plausible to suppose that by more knowable by nature, Aristotle means to describe those things which are more in line with fact-with the true, objective state of the world. And this, he thinks (not too implausibly), might be far removed from what we are ordinarily more aware of. But what might those objects be?

Aristotle goes on to say that the things which are clearer to us are "mixed" or "compounded," or perhaps even "confused" (sunkechumena, 184a22). Aristotle seems to be talking about the confused nature of our sense experience or perhaps the compounded, nonsimple conceptual states we often find ourselves in. He then says that the things more knowable, the gnorima, come about from these confused things more clear to us only after the principles have divided (perhaps "analyzed," diairousi) them. We of course now see the importance of principles for Aristotle's methodology once again — by their very division of the confused things immediate to us, they begin to arrive at things more knowable by nature - but we also remain uncertain about just what sort of division Aristotle is talking about. Thankfully, this is also built up by Aristotle in the next few sentences, those which have been found by most commentators to be most obscure.

Aristotle begins at $184 \mathrm{a} 23$ with what many have found to be the most jarring part of the opening 1.1 discussion. Aristotle says that we must start with the universal (katholou), more knowable by perception (ten aisthesin), and arrive at particulars. ${ }^{23} \mathrm{He}$ also means to

\footnotetext{
${ }^{22}$ If the reader would like to consider the passage in conjunction with my explication, I have reproduced the lines on pages 4, 5, and 6 of this essay (184a10-184b14).

${ }^{23}$ In direct contradiction with what he says at Pos. An. 1.2, 72a 7 and elsewhere.
} 
say, then, by direct implication, that the universal (which, as he will go on to say in 24, is a kind of "whole") is that which is clearer and more knowable to us. This many have found to be particularly difficult. But it does not seem to be a slip on Aristotle's part (see similarities with 1.7, 190a30-33), and I do not mean here to resolve the tension by appealing to other evidence from the Posterior Analytics. So what might Aristotle mean? Indeed, to put the question we have been building to in a little clearer form: what does Aristotle mean when he says that those things which are clearer and more knowable to us are compounded and universal/whole? My answer, which I believe is particularly well evidenced in 1.2, is that the universal or whole Aristotle has in mind is the immediate, uninterpreted data of sense experience - which, as one might expect, can range from certain "limited" wholes, such as genera of animals, to, at broadest level, nature itself. This of course I will be explaining in greater detail over the next few pages.

In the final few sentences Aristotle tries to fill in this account a little further, but it lacks clarity owing to its extreme terseness. I hope my exposition can correct for that. Aristotle says at $184 \mathrm{~b} 10$ that words (onomata) are related to the account (logos) in the same way as whole is to particular. Then he says: "a word like 'circle' indicates a whole indiscriminately, whereas the definition (horismos) of a circle divides it into particulars (ho de horismos autou diairei eis ta kath' hekasta)" (11). Aristotle means here, I think, that the word itself "circle" is something like the uninterpreted whole (more knowable by perception) I mentioned in my last paragraph, and that further elements of a definition make it into particulars, often of more fundamental natures. For instance, a definition of circle might be "a shape whose sides are all equidistant from its center"-taking a compound (a sunkechumenon) and reducing it into its simples.

Drawing from all this, we may say that whatever the compound (sunkechumenon) is in the following discussion in books 1 and 2, it will be a whole that the principles (archai) divide into particulars. And it is in 1.2, where Aristotle begins his treatise in earnest after introductory remarks, that we start with what is clearer and more knowable to us (a whole) in a discussion about nature (peri phuseos) to be later divided by principles (the precise nature of which constitutes the subject matter of the entire of book 1). In 1.2, Aristotle says that the monists - those who claim that all there is is one and motionless - are not properly speaking engaged in discussions about nature. They ignore, in effect, what is immediately clear and 
more knowable to us (and which Aristotle says later at 2.1 193a2-5 it would be ridiculous to try to show), namely, that nature exists and is related to change $(1.2,185 \mathrm{a} 12-14)$. This, I take it, is meant to provide us with the uninterpreted starting-point of Aristotle's natural sciencethe whole and universal that Aristotle describes in 1.1- to be later analyzed and "divided" into particulars by the principles (once we have arrived at their nature and number, as we do at the end of 1.9).

It remains to be said, then, how I think my interpretation of the very beginning of book 1 plays a certain ordering role in the course of Physics 1 and 2. I think 2.1 provides my account with particularly strong evidence.

On my reading, Aristotle says in 1.1 that for us to say we have knowledge about nature (peri phuseos), we must begin with principles (first in order of explanation) and get clear on what we mean we talk about them, and then use these principles in a definition (horismos) to divide the whole into particulars. Book 1, on my interpretation, just is the exercise of getting clear on principles for a natural science (about knowledge peri phuseos). In this way my interpretation fits with certain traditional interpretations of book 1 as the "book about principles" (peri archon). ${ }^{24}$ I took it as convincing that the "whole" in our case was, quite broadly, nature (phusis) — as evidenced, I believe, in 1.2 — and that the number and nature of the principles is filled in by book 1.

Now in 2.1, we get Aristotle's famous definition (horismos) of nature: "Nature is a sort of principle (arche) and cause (aition) of change and remaining unchanged in that to which it belongs primarily of itself, that is, not by virtue of concurrence" (192b20-23). Notice that in this very definition-what Aristotle told us would divide the whole into particulars - we get mention of a principle (arche). Now, on my reading, precisely why Aristotle does this (and why book 2 follows book 1) is because Aristotle needed to start formulating his definition for the uninterpreted whole (phusis) by first getting clear on what sort of thing a principle is (the work of book 1). Somewhat more obscurely, I think that Aristotle, in his discussion of causes, beginning in 2.3 and ending in 2.7, fills in the remaining work about how a thing is said to be natural (and so "divided into particulars" in four different ways).

\footnotetext{
${ }^{24}$ See Ross 5-6. Simplicius 801.13 (Ross 6).
} 


\section{Conclusion}

At this point I think we may safely summarize my approach (what I call the "physical" approach to the methodology presented in Physics 1.1) and list its advantages over what I have called the "dialectical" and "scientific" approaches.

On my reading, the main thread of argument in Physics books 1 and 2 is dominated by the methodology discussed in Physics 1.1 (not present somewhere else in the Aristotelian corpus), and so follows the general structure demanded by Aristotle's insistence that knowledge results from a definition (horismos) which takes a universal/whole (katholou, holon), more knowable and more clear to us by perception (ten aisthesin), and divides it (diairei) by means of principles (archai) into particulars which are clearer and more knowable by nature (phusei). This structure, reinforced by certain elements of the discussion of Physics 1 and 2 I have mentioned, demands that we start with a universal (which I have identified in the Physics as phusis itself) and that we get clear on the principles needed to divide this universal. This of course is borne out in the actual structure of Physics 1 and 2. The definition comes later at 2.1, after principles for the definition have been adequately discussed and numbered.

We now see that the physical approach is neither dialectical nor scientific. The dialectical interpretation emphasizes Aristotle's moving from what is more clear to what is less clear (as in the Topics) and the certain bits of supposed ordinary linguistic data in the Physics. But on the physical reading we are meant to start with wholes (katholou/holon) more known to us by sense perception, and arrive at what is less clear to us, but what is, importantly, clearer by nature. In this way the physical reading resists the identification of Aristotle's method in the Physics with that of the Topics. Indeed, it seems to be the point of much of Physics 1 to show the dangers of dialectic that begins not with a universal known from sense perception but from supposed endoxa (viz., the errors of the monists described in Physics 1.2-4).

The scientific interpretation, on the other hand, wants to draw a direct equivalence between the method described in Physics 1.1 and that of the Posterior Analytics. The physical interpretation resists this move as well. The Posterior Analytics states emphatically that the particulars are better known than the wholes/universals, whereas the Physics states the 
opposite. The physical interpretation does not try to explain away this tension, but rather reaffirms the whole/universal (phusis), gathered from the very sense perception that a natural world exists and that there is change in its parts, as the basic starting-point for Aristotelian natural science.

Evan Dutmer

Culver Academies

Bibliography

Aristotle (1984). The Complete Works of Aristotle. Vols. 1 and 2. Princeton: Bollingen.

Aristotle (1983). Physics: Books I and II. Trans. W. Charlton. Oxford: Clarendon, 1983.

Bolton, Robert (1988). “Aristotle's Method in Natural Science: Physics I.” Aristotle's Physics: A Collection of Essays. Ed. Lindsay Judson. Oxford: Clarendon.

Cleary, John (1994). "Phainomena in Aristotle's Philosophic Method.” International Journal of Philosophical Studies, 2: 61-97.

Hankinson, R. J. (1995) "Philosophy of Science" and "Science." The Cambridge Companion to Aristotle. Ed. Jonathan Barnes. Cambridge: Cambridge.

Irwin, Terence (1988). Aristotle's First Principles. Oxford: Clarendon.

Kelsey, Sean (2003). “Aristotle's definition of nature.” Oxford Studies in Ancient Philosophy 25: 59-87.

Lennox, James (2008). “"As if we were investigating snubness': Aristotle on the prospects for a single science of nature." Oxford Studies in Ancient Philosophy 35: 149-186.

Owen, G. E. L. (1962/1986) Logic, Science, and Dialectic. London and Ithaca: Cornell University Press.

Ross, W. D. (1936) Aristotle's Physics: A revised text with introduction and commentary. Oxford: Clarendon.

Ross. W.D. (1962) "Philosophy of nature." Aristotle: A complete exposition of his works and thought. Cleveland: Meridian.

Simplicius (1997). On Aristotle's Physics 2. Trans. Barrie Fleet. Ithaca: Cornell University Press.

Themistius (2012). On Aristotle's Physics 1-3. Trans. Robert B. Todd. Ithaca: Cornell University Press.

Waterlow, Sarah (1988). Nature, Change, and Agency in Aristotle's Physics. Oxford: Clarendon. 